\title{
United States: Publication of Financial Sector Assessment Program Documentation- Technical Note on Basel II Implementation Preparedness in the United States
}

This Technical Note on Basel II Implementation Preparedness for the United States was prepared by a staff team of the International Monetary Fund. It is based on the information available at the time it was completed in May 7, 2010. The views expressed in this document are those of the staff team and do not necessarily reflect the views of the government of the United States or the Executive Board of the IMF.

Copies of this report are available to the public from

International Monetary Fund • Publication Services

700 19th Street, N.W. • Washington, D.C. 20431

Telephone: (202) 6237430 • Telefax: (202) 6237201

E-mail: publications@imf.org • Internet: http://www.imf.org

\section{International Monetary Fund Washington, D.C.}


FinANCIAL SECTOR ASSESSMENT PROGRAM

UNITED STATES OF AMERICA

BASEL II IMPLEMENTATION PREPAREDNESS IN THE UNITED STATES

TECHNICAL NOTE

MAY 2010

INTERNATIONAL MONETARY FUND

MONETARY AND CAPITAL MARKETS DEPARTMENT 
4079528 
Glossary
A. Introduction. 4
B. Overall Conclusion.. .5
C. Plans and Resources . .6
D. Capital Definition, Scope of Application, and Impact................................................12
E. Standardized Approach to Credit Risk ..................................................................... 15
F. Internal Ratings Based Approach to Credit Risk ..................................................... 16
G. Advanced Measurement Approach (AMA) for Operational Risk ..................................19
H. Pillar 2: Supervisory Review Process ........................................................................20
I. Pillar 3: Disclosure and Market Discipline..............................................................23 


\section{GLOSSARY}

$\begin{array}{ll}\text { AIRB } & \text { Advance Internal Ratings Based } \\ \text { AMA } & \text { Advanced Measurement Approach } \\ \text { BCBS } & \text { Basel Committee for Banking Supervision } \\ \text { BCP } & \text { Basel Core Principles } \\ \text { BHC } & \text { Bank Holding Companies } \\ \text { CP } & \text { Core Principles } \\ \text { DI } & \text { Depository Institution } \\ \text { FBAs } & \text { Federal Banking Agencies } \\ \text { FRB } & \text { Federal Reserve Board } \\ \text { FSAP } & \text { Financial Sector Assessment Program } \\ \text { FTE } & \text { Full Time Equivalent } \\ \text { ICAAP } & \text { Internal Capital Adequacy Assessment Process } \\ \text { IMF } & \text { International Monetary Fund } \\ \text { IRB } & \text { Internal Ratings Based } \\ \text { LDCE } & \text { Loss Data Collection Exercise } \\ \text { LTV } & \text { Loan-to-Value Ratios } \\ \text { OCC } & \text { Office of the Comptroller of Currency } \\ \text { QIS } & \text { Quantitative Impact Studies } \\ \text { QT } & \text { Qualification Teams } \\ \text { SCAP } & \text { Supervisory Capital Assessment Program } \\ \text { U.S. } & \text { United States }\end{array}$




\section{A. INTRODUCTION}

1. As part of the Financial Sector Assessment Program (FSAP) of the United States, the International Monetary Fund (IMF) assessment team performed a high-level assessment of preparedness for implementation of Basel II in the United States ${ }^{\mathbf{1}}$. At the time of the FSAP, Basel II (advanced approaches only) had been adopted (in 2007) as a rule for certain "mandatory" or "core banks" and their Bank Holding Companies (BHCs). However, implementation of these rules was not complete, in the sense that banks' capital calculations at the time of the FSAP assessment were based on Basel I. Accordingly, implementation of Basel II was not formally assessed as part of the FSAP. Instead, the assessors adapted a simplified set of Basel II implementation assessment criteria from the full criteria normally used by the IMF (as agreed with the Basel Committee for Banking Supervision (BCBS)) for a stand-alone Basel II assessment. The authorities agreed to submit a self-assessment against these simplified criteria. Assessors focused on the advanced approaches rule as that is the only Basel II rule that the United States has currently implemented.

2. The assessment team met with staff of Federal Banking Agencies (FBAs) involved in Basel II implementation and reviewed certain documents. Currently, the Federal Reserve Board (FRB) and the Office of the Comptroller of Currency (OCC) are primarily involved in the implementation process because they are the primary supervisors of the banks moving to Basel II. In future, depending on which other banks become core banks or opt in to Basel II, other FBAs will also be involved in detailed implementation. As well, the assessment team met with certain banks that are implementing Basel II. As a technical note that is not part of the Basel Core Principles (BCP) assessment, no ratings were assigned related to Basel II implementation. Findings for some Core Principles (CPs) in the FSAP are relevant for Basel II implementation, and were taken into account in this note.

3. This note and assessment relates to Basel II rules and implementation as they existed at the time of the assessment in October 2009. The BCBS proposed various enhancements to the Basel II framework in 2009. Some of these have been agreed and some others are in the comment phase before final adoption by the BCBS. The U.S. authorities have been active in the development of these proposals. As they were only recently promulgated by the $\mathrm{BCBS}$, the rules related to trading book exposures and other matters were not assessed. FBAs indicated they intend to implement those by year-end 2010, in line with the schedule proposed by the Basel Committee.

4. The body of this technical note follows the order of the criteria that were used.

\footnotetext{
${ }^{1}$ The main author of this note is Nicholas Le Pan, IMF Consultant; ex-Head of the Office of the Superintendent of Financial Institutions, Canada and ex-Vice Chairman of the Basel Committee for Banking Supervision).
} 


\section{B. Overall Conclusion}

5. The FBAs are conducting a high quality implementation of the advanced approaches for core banks. The skills and resources being brought to bear are impressive and substantial. While inter-agency disagreement in policymaking regarding Basel II has been a factor in the run-up to the implementation and may not have been fully resolved, inter-agency coordination between the main FBAs currently involved (the FRB and OCC) is of high quality and a model for other inter-agency endeavors. In part, this is due to the sustained level of focus that Basel II has received from FBAs at all levels of these organizations.

6. There remains uncertainty in banks about the status of Basel II in the United States going forward. For banks, some of this relates to how the implementation will work in practice, whether banks will ever be permitted to exit parallel runs or the floors, the extent to which the FBAs will actually use Pillar 2 assessments that banks perform, or whether this will be a compliance exercise, and what, if any of the standardized approach will be implemented. Apprehensions related to this uncertainty are understandable. Despite the leading role played by the United States in developing Basel II, considerable and protracted inter-agency disagreement delayed U.S. implementation, and these interagency disagreements still do not appear to be fully resolved. Moreover, industry and market uncertainty have been exacerbated by the recent crisis and the significant adjustments that are happening to the Basel II standards. To ensure success, it will be important for the authorities to adopt policies and processes that will reduce these uncertainties. The agencies have indicated they are continuing to work domestically and with the Basel Committee to strengthen the Basel II framework, including issues associated with the use of internal models for determining capital requirements.

7. Certain policy choices the authorities have made or may make related to allowing banks to choose the capital regime that applies to them (beyond the options in the Basel II structure) may open up arbitrage possibilities that the authorities need to take into account going forward. Assessors encourage the FBAs to finalize the rest of their Basel II adoption/implementation process in order to reduce uncertainty for banks.

8. This note contains a number of suggestions for the FBAs to enhance their review of progress in implementation of advanced approaches in the next one to two years so as to ensure they remain on track for a high-quality implementation. Those recommendations concern such matters as having sufficient ongoing resources, desirable cross-system detailed reviews of implementation in various areas, and use of the Pillar 2 process to enhance capital adequacy assessments by banks. 


\section{Plans and Resources}

9. Criteria: The supervisor should be able to demonstrate a feasible plan for robust project management, disclosure, good governance, and oversight of Basel II implementation. This includes a Basel II implementation strategy objective and plans that: fit into a country's overall supervisory priorities; appropriately take account of the readiness and capacity of the supervisory authority and the banking system; and are disclosed to the public and discussed with banks.

10. On December 7, 2007, the FBAs issued a final rule (advanced approaches rule) implementing the advanced approaches of the Basel Committee's Basel II capital adequacy framework (Basel II or New Capital Adequacy Framework). In the United States, the advanced approaches rule is mandatory for certain banking organizations (core banks) and voluntary for others (opt-in banks). (See 72 FR 69288). Core banks are required to implement the advanced Internal-Ratings Based (AIRB) approach, Advanced Measurement Approach (AMA), and the market risk rule in Pillar 1. They also must implement Pillar 2 and Pillar 3 requirements. Core banks account for a substantial portion of the banking system assets in the United States.

11. Banks and BHCs are subject to the advanced approaches rule if they meet either of two independent threshold criteria: (i) consolidated total assets of US\$250 billion or more; or (ii) consolidated total on-balance sheet foreign exposures of US\$10 billion or more, each as reported on the most recent year-end regulatory reports. Authorities describe these banks as "the most internationally active." Assessors believe that other non-core banks may eventually be deemed to be sufficiently important, or sufficiently internationally active and should be strongly encouraged, at an appropriate time, to opt in to the advanced approaches rule

12. As at the time of assessment, there are 14 banking groups that meet these core criteria. In addition, the advanced approaches rule allows other banks who meet the Basel II qualifying criteria for advanced approaches to opt in to this rule in the United States. The FBAs indicated that there are two to three banks that have indicated their intention to opt in (typically banks with foreign parents on Basel II) and two to three more have expressed an interest in doing so.

13. Each Depository Institution (DI) subsidiary of a core or opt-in bank/BHC is itself required to apply the advanced approaches rule unless specifically exempted from this requirement by its primary federal supervisor.

14. Under the rule, a core bank must plan to complete its parallel run within 36 months of becoming subject to the rule: for the initial group of core banks, this implies beginning parallel run no later than April 2010. After a bank successfully exits its parallel run (which requires approval), the advanced approaches become the formal minimum capital requirements for the bank, subject to floors that are in place for a minimum three-year period. 
15. In July 2008, the FBAs issued guidance related to the overall qualification process (qualification guidance). This guidance addressed: the need for banks to have all systems and processes functioning well prior to the start of parallel run; the need for a robust and dynamic implementation plan as a key communication tool for dialogue between the bank and its supervisors; the need for robust qualitative and quantitative validation; and reiterated the numerous options and approvals that are embedded in the rule. FBAs also issued guidance on Pillar 2 in $2008 .^{2}$

\section{Additionally, in 2007, the FBAs proposed for comment a rule to allow non-} mandatory banks to adopt the Basel II standardized approach for credit risk and the basic indicator approach for operational risk. The proposed rule was optional for those banks - that would also be permitted to remain on the current risk-based capital rule, which is based on Basel I. This proposal contained high-level Pillar 2 requirements and additional disclosures based on Pillar 3. The main difference in the U.S. proposed standardized approach, relative to the Basel II standardized approach, is a more granular treatment of exposures to residential mortgage exposures based on loan-to-value (LTV) ratio bands. For some LTV ratios, the proposed capital treatment would be higher than under Basel II standardized, which authorities indicated they believed was appropriate for the U.S. market. Certain other countries such as Australia and Brazil have followed a similar approach.

17. The standardized rule remains at the proposal stage. Comments have been received, but there is no indication from the authorities of their intention as to whether or when the proposal will be adopted, and if it proceeds, what alterations might be introduced. Assessors did not focus on this proposal during the assessment.

18. The overall strategy for Basel II remains somewhat in flux in the United States with banks, and others the assessors met, indicating that they would benefit from greater clarity about the status of Basel II going forward. The rules now in place were implemented after a long period of discussion, and with considerable inter-agency difference of views. There also remains a difference of views between FBAs about Basel II today, including among those with whom the assessment team met.

19. The assessment team discussed with FBAs the policy of allowing banks the possibility of being on one of three separate capital rules. This policy is understandable given the heterogeneity within the U.S. banking sector, but it introduces risks of inappropriate results. For example, some complex banks that choose not to opt in to the advanced approaches may be doing so to avoid detailed operational and risk management requirements and related capital charges. Additionally, allowing banks to opt out of the standardized approach and remain on the Basel-I based existing capital rules, means that those banks would not face additional capital charges for higher-LTV mortgages that would

${ }^{2}$ http://www.federalreserve.gov/boarddocs/srletters/2008/SR0804a1.pdf 
apply under the Basel II standardized approach. They would also avoid capital charges for operational risk.

20. For the advanced approaches rule, the FBAs have robust plans and processes in place to ensure effective oversight of Basel II implementation and qualification, including program managers and dedicated staff responsible for Basel II oversight. The individuals involved in implementation are responsible for developing and communicating each agency's respective supervisory strategies and ensuring consistency in approach across the FBAs as well as across firms. Staff and senior leaders that the assessors met demonstrated a comprehensive and sound understanding of Basel II implementation challenges and effective ways to meet them.

21. Each agency has a well-articulated overall Basel II strategy that has been disseminated to appropriate supervisory staff and communicated to relevant banking organizations. At the largest institutions, the dedicated staff has developed firm-specific supervisory strategies that focus on the specific implementation status, issues, knowledge gaps, and concerns for that institution. There appeared to be excellent interaction and involvement and integration of front-line supervisory teams, risk specialists, and Basel II specialists.

22. Supporting these strategies are high-quality examination documentation requirements that ensure examiners address all aspects of the rule, and provide a common framework for summarizing an individual firm's readiness. Program management capabilities appear to be well-developed and working well in practice.

23. FBAs involved in the current implementation of the advanced approaches rule (the FRB and OCC) demonstrated a very high degree of cooperation and coordination in implementation efforts. Several commentators on the U.S. system noted that recent Basel II efforts were a model for supervisory cooperation going forward.

24. It will be important to extend this framework for cooperation and coordination to other FBAs when they will be required to assess implementation as banks they supervise opt in to the advanced approaches under Basel II.

25. Under the U.S. advanced approaches rule, a core bank must adopt a boardapproved implementation plan that incorporates completing a parallel run within 36 months of the bank becoming subject to the rule. For the initial group of core banks, this implies adopting implementation plans by October 2009 and beginning parallel runs no later than April 2010. Approval is required to exit parallel run and enter a three-year period where the bank's capital calculation is according to Basel II subject to declining floors. Approval is required to move between floor stages and to exit the floor period. At the time of the assessment, one bank had commenced its parallel run period.

26. In implementing Basel II for core banks, the U.S. has looked for a high proportion of the banks' portfolios to be compliant with the advanced approaches. It has not made use of the partial roll-out flexibility to any considerable degree. As a general 
policy, FBAs have also looked for Basel II preparedness at banks to be of high quality before banks enter parallel running.

27. Criteria: Assessors should be satisfied that the supervisor has adequate resources to implement Basel II, including a budget that permits effective Basel II implementation. This includes staff in sufficient numbers and with skills commensurate with the size and complexity of the institutions implementing Basel II, and appropriate for the Basel II approaches being implemented.

28. Assessors saw evidence that material amounts of resources have been deployed in the implementation effort. The level of resources appears appropriate given the size and complexity of implementation for mandatory banks. Each of the two main FBAs involved has allocated some five or six FTEs per core bank in implementation efforts. Considerable high-quality expertise in risk quantification and risk analytics is also available to the teams.

29. FBAs face challenges over the next few years as a "hump" of assessment of implementation plans, parallel runs periods, and approvals relating to floor periods will be required. This additional work will occur in a period when "normal" supervisory intensity will remain high due to the aftermath of the financial crisis and the remedial actions that have been found necessary as a result. FBAs are well aware of these challenges and are gearing up to face them. The FBAs believe that efficiencies they can gain from experience in dealing with the first few cases can assist in reducing the resource demands. It is likely that there will be other demands going forward on the analytical and technical resources that have been made available for Basel II implementation.

30. While efficiencies are undoubtedly possible based on learning from the initial cases, assessors believe that the FBAs may be underestimating the resource challenge. In 2010, FBAs should more explicitly consider the likely multi-year resource demands they will face in Basel II implementation and ensure that sufficient resources are available.

31. Basel II requires supervisors to determine on an ongoing basis that the qualifying conditions are being met. As well, certain aspects of Basel II implementation for advanced approaches, including Pillar 2, normally require some adjustment in supervisory programs. This can be more important in the early years of implementation. It is usually not possible to implement the advanced approaches without some permanent additional resources being committed.

32. Both management in charge of Basel II implementation and senior management in charge of FBAs are aware that, after initial approval processes are complete, the level of ongoing resources in supervision of core banks will have to be higher than pre-Basel II. There is not a high degree of precision as to what increased need may be and the FBAs are, to some extent, rightly waiting to determine this when information on resource demands of this phase are clearer. More generally, FBAs tend to use a current year and one-year forward budget process. The drawback of this approach is that explicit consideration of Basel II resource demands necessary to sustain the high quality 
implementation can be lost. FBAs should explicitly take account - in each budget cycle for the next few years - of the resources being used in Basel II implementation and assess their adequacy against experience to date. This should be based on explicit monitoring of the resource implications of Basel II for supervisory teams and specialist resources.

33. In addition to the program management role described above, the FBAs are coordinating their Basel II efforts at each banking organization to make the reviews more efficient and to ensure consistent application of the advanced approaches rule across all entities within the organization. The supervisory teams that the assessors met are aware of their responsibilities. On-site supervisory teams are responsible for the ongoing supervision of the institutions, including Basel II, and appeared to have skills commensurate with the size and complexity of the institutions that they supervise. Many team members have particular skills in advanced risk management practices. These on-site teams are augmented by input and assistance provided by experts in the area of policy and quantification, as well as other staff with specialized skills from within and across the FBAs.

34. The United States appears to be managing well the hand-off and coordination challenge between various groups within each FBA. Assessors saw ample evidence of appropriate levels of skills and awareness in the supervisory teams that they met. Supervisory team leaders are aware that Basel II implementation is one of their top priorities.

35. The FBAs have developed a comprehensive training program, with training targeted across skill and experience levels. Classes are generally aligned along risk dimensions, ranging from high level introductory and overview courses, to in-depth and advanced level seminars. Staff within each agency has access to online training tools covering the breadth of the framework. In some cases, classroom and individual training is augmented by applied workshops that partner risk experts with field staff to discuss specific institutional issues and challenges, and to share experiences and knowledge across teams and FBAs.

36. Criteria: Adaptations of supervisory systems should take account of initial approval requirements and the need for ongoing monitoring and assessment of Basel II in banks.

37. The ongoing qualification requirements are described in Section 23 of the advanced approaches rule. Each agency has developed, or is developing, processes for reaching the numerous decisions involved in initial and ongoing qualification. Staff involved with the Basel II qualification decision process is made aware of these processes through discussions and training.

38. The ongoing adjustments in supervisory processes necessitated by Basel II have not been fully determined at this stage. Assessors encourage FBAs to finalize these during 2010 .

39. Criteria: Supervisors should have the experience and expertise to analyze bank plans for Basel II implementation, and effectively challenge them, when appropriate. Assessors should ask for examples of such challenges. 
40. Staff at each of the FBAs is experienced in reviewing, analyzing, and providing detailed feedback on banking organizations' draft implementation plans. The advanced approaches rule articulates high expectations for implementation plans and is supported by the qualification guidance that includes a section specifically addressing implementation plans. The FBAs view the implementation plan as an important benchmark for measuring compliance with the advanced approaches rule. To date, the FBAs have reviewed all core banks' implementation plans. Detailed feedback was provided to each institution on their draft implementation plan and gap analysis. In many cases, the FBAs asked for, and received, modifications or amendments to the plans.

41. Staff of the FBAs, whom the assessors met, demonstrated a high degree of expertise in Basel II and related matters. Assessors were satisfied that FBAs were able to exercise effective challenge of banks plans and implementation. Expertise and ability to make appropriate judgments were evidenced in the quality of staff assessors met.

42. Criteria: Supervisors should have adequate systems to ensure due process, analysis and review of banks' Basel II options and models, as well as quality control over treatment of banks applications for use of Basel II options and models. Supervisors must have the experience and expertise necessary to exercise sound judgment in treating these applications.

43. FBAs have developed processes to review and analyze each banking organization's implementation of the advanced approaches during and after the parallel run. The FBAs also have due process in place to allow for notice and response to the banks of results from the review and analysis. In practice, the supervisory processes have been evidenced through on-site examination work that has been conducted at one banking organization during its parallel run period. Staff with appropriate expertise have reviewed each approach subject to approval and provided applicable feedback.

44. Assessors discussed the FBAs' approach to ensuring consistency of approach in reviewing implementation plans and are satisfied that it was effective. Ensuring consistency on an ongoing basis will be more challenging as banks are not in the parallel run period at the same time. Ensuring consistency requires not only the same standards, but also the processes to enhance the confidence that the standards and judgments are being applied consistently, and that differences in treatment are commensurate to the differences between banks. As international experience suggests, being able to consider several banks at the same time in a peer comparison process can be very helpful in this regard, but is rendered more difficult in a sequential process. Having constancy of core staff and a strong review process, as the FBAs have, can partially compensate for this.

45. Assessors discussed with FBAs the review process with respect to supervisory and approval decisions, and are satisfied that it is effective and robust. As more of the responsibility for Basel II work transfers to on-site supervisory teams and continuous supervision, it will be important that FBAs review their process for internal review and oversight to satisfy themselves that goals for high quality and consistent implementation continue to be met. Banks that the assessment team met reported some issues of 
inconsistency, but these did not seem to be out of line with experience elsewhere. As other FBAs become more active in Basel II implementation (as the number of qualifying banks expands), it will be important for links to be built with the FRB and OCC to ensure ongoing consistency.

\section{Capital Definition, Scope of Application, and Impact}

46. Criteria: Supervisors should require the framework to be applied to internationally active banks on a fully consolidated basis consistent with paragraphs 20-39 of the Basel II framework. The consolidation perimeter should include any holding company that is the parent entity in a banking group which includes banking, insurance, and/or other financial subsidiaries.

47. In general, U.S. implementation of the advanced approaches rule meets the consolidation requirements of the Basel II Accord, or is more conservative.

48. The advanced approaches rule excludes assets held in an insurance underwriting subsidiary of a BHC from the asset threshold criterion because the rule was not designed to address insurance underwriting exposures. However, insurance subsidiaries and their assets must be consolidated for purposes of determining the BHC's risk-weighted assets and calculating its capital requirements under the advanced approaches rule.

49. As required by statute, ${ }^{\mathbf{3}}$ assets and liabilities of a financial subsidiary of a depository institution (DI) are not consolidated with those of the DI for risk-based capital purposes. Moreover, the DI must deduct its equity investment (including retained earnings) in the financial subsidiary from regulatory capital-50 percent from Tier 1 capital and 50 percent from Tier 2 capital. Conversely, a BHC generally fully consolidates the assets and liabilities of financial subsidiaries of its subsidiary DIs, and does not deduct from its regulatory capital the DI's equity investments in their financial subsidiaries.

50. In recognition of potential burden issues, the rule allows the FRB to exempt any BHC from mandatory application of the advanced approaches. The FRB will make such a determination in light of the BHC's asset size (including subsidiary DI asset size relative to total BHC asset size), level of complexity, risk profile, or scope of operation. Similarly, the rule allows a primary federal supervisor to exempt any DI under its jurisdiction from mandatory application of the advanced approaches. A primary federal supervisor will consider the same factors in making its determination. To date, no exemptions from the advanced approaches rule have been approved across the FBAs, but several have been requested. FBAs advised the assessment team that any exemptions would be rare.

51. U.S. subsidiaries of foreign banks that are on Basel II in their home country are not required to be on Basel II in the United States, unless the subsidiary meets the

${ }^{3} 12$ USC 24a(c)(1). 
criteria for a core bank. Such subsidiaries may opt in to the advanced approaches rule, and a few will do so in future. As Basel II standardized and foundation approaches are not available in the United States, subsidiaries of foreign banks are using the Basel I-based rule and then performing various adjustments to calculate Basel II capital at the parent company level. This would often necessitate two capital calculations for the subsidiary.

52. Criteria: Significant minority interests in these types of financial institutions, as well as significant investments in commercial entities, should be consolidated to the extent envisaged by the framework, and deductions from capital made according to the framework.

53. Assessors discussed the approach to consolidation/deduction with the FBAs. The advanced approaches rule's consolidation and deduction requirements are substantially consistent with the Basel II. Any departures result in more conservative capital calculation, as noted in paragraph 49 above, than envisaged in the New Capital Adequacy framework.

54. Criteria: Supervisors should require application of the framework to any internationally active bank at the sub-group level (paragraph 22).

55. As described above, each DI subsidiary of a core or opt-in bank is itself required to apply the advanced approaches rule unless it receives a specific exemption from its primary federal supervisor.

56. Criteria: Supervisors should also be able to demonstrate that they periodically test the adequacy of capital of banks on a stand-alone basis.

57. The U.S. supervisory process expects examiners to evaluate an institution's capital separately at the BHC and at each DI in the banking group. Public quarterly reporting of capital ratios is required at each DI in the banking group, as well as the top-tier U.S. banking holding company. Additionally, the U.S. rule works to require an Internal Capital Adequacy Assessment Process (ICAAP) at each level in the banking group, though the bank-ICAAP can be based on relevant parts of the group-wide ICAAP. Assessors were not able to review how the ICAAP assessment within a group works in practice at this stage of implementation.

58. Criteria: Supervisors should have performed one or more quantitative impact studies (QIS), within or outside the Basel-sponsored framework, to assess the impact of Basel II on banks' capital adequacy levels. The results should have been analyzed in advance of implementation, and thereafter through ongoing analysis during parallel running. Supervisors should be able to demonstrate that they understand the prudential implications of material changes in capital, and that they are satisfied that capital levels will remain adequate to buffer underlying risk.

59. The FBAs initiated several quantitative impact studies prior to implementation of the advanced approaches rule in the United States. A fourth quantitative impact study was initiated in 2004 with the objective of gaining a better understanding of the potential effects of a Basel II risk-based capital regime on U.S institutions. The subsequent analytical 
work focused on identifying the extent to which the reduction and dispersion in minimum risk-based capital requirements indicated by the study reflected the risks facing institutions, differences in the state of institutions' data systems, and their overall readiness to implement the Basel II framework, as well as aspects of the framework itself that might produce results that did not appropriately reflect underlying risks. (See QIS-4 Summary Findings at: http://www.federalreserve.gov/boarddocs/press/bcreg/2006/20060224/attachment.pdf.)

60. The FBAs committed by regulation to undertake a study to evaluate the advanced approaches and determine if there are any material deficiencies. An institution would generally not be permitted to exit the third transitional floor period if the study determines there are material deficiencies that cannot be addressed by then-existing tools or by amendment to the advanced approaches.

61. The FBAs developed extensive supervisory reports to collect data in addition to the disclosures required under Pillar 3 from banking organizations using the advanced approaches. Currently, one banking organization is in parallel run and is submitting these reports; a number of banking organizations are expected to follow suit in 2010.

62. Assessors noted the considerable, high-quality work done by FBAs in the period leading up to the rulemaking to assess impacts. However, some of this is now dated. Recent stress conditions have underscored the importance of ensuring data inputs are representative of economic downturns and the supervisory formulas are calibrated appropriately. Once a number of banks are in parallel run, it will be possible for the FBAs to update their assessment of impacts. Such an assessment should be possible at year-end 2010 and 2011. The assessment team supports the FBAs' intention to perform such an analysis.

63. There has been no assessment on an aggregate basis of the impact of adopting the Basel II standardized approaches for smaller banks (there were specific analyzes of competitive impacts done previously). If the authorities do proceed to implement the standardized approaches for smaller banks, it would be desirable to perform some assessment of impacts and the possibility for arbitrage between approaches.

64. In 2008, the FBAs participated in an Operational Risk Loss Data Collection Exercise (LDCE) sponsored by the Basel Committee's Standards Implementation Group. LDCE participants included 23 U.S. financial institutions. The LDCE collects data on individual loss events and loss scenarios, as well as capital estimates. Among other purposes, the LDCE is being used to benchmark capital estimates to make sure they fully reflect banks' actual operational risk exposures.

65. Criteria: The capital definition should be set out in regulations, and be consistent with paragraph 41 of the framework. Where supervisors allow the inclusion of nontraditional capital elements, they should satisfy themselves that they meet, in substance, the relevant criteria for inclusion set out in the Basel framework and associated documents.

66. Tier 1, Tier 2, and total capital are defined in the advanced approaches rule. They incorporate by reference, the elements of capital and many of the deductions in the 
general risk-based capital rules, and are generally consistent with paragraph 41 of the New Accord. However, as noted in the BCP assessment, the general risk-based capital rule, and thus the advanced approaches rule, allows certain intangibles to count for a very high portion of Tier 1 capital.

67. Additionally, until March 31, 2011, banks under the advanced approaches rule are allowed to continue to have up to 25 percent of their Tier 1 capital in so-called innovative or hybrid instruments, compared to the international standard of 15 percent.

\section{E. StAndardized APProach to CREDit RiSK}

68. Criteria: Regulations and a supervisory process should be in place to require banks to meet the requirements and risk weights for calculating capital for credit risk using the standardized approach for individual claims, in a way which is consistent with the Basel II framework. Any differences should reflect a more conservative approach based on local default experiences.

69. The standardized approach is not currently allowed in the United States. While a proposal was made in 2006 to implement the standardized approach on an optional basis for banks not subject to the advanced approaches, the proposal has not been finalized. The status of the proposed rule is not clear. The FBAs advised they are in the process of developing another version of the standardized approach for public comment.

70. The assessment team did, however, review the proposed standardized approach at a high level. The rule is consistent with the standardized approach outlined in the New Accord and more conservative in some respects as noted below (leaving aside definition of capital issues that are covered elsewhere in this note and in the BCP assessment). The material difference is the proposal's treatment of residential mortgages, which is based on LTV ratios. Risk weights for residential mortgages would range from 20 percent to 150 percent, depending on the LTV for a given residential mortgage exposure. As proposed, significantly more mortgages would receive a higher than 35 percent risk weight than would be the case under the approach outlined in the New Accord. The FBAs believe that the wider range of risk weights proposed in the U.S. standardized approach is more risk sensitive and conservative than the single 35 percent risk weight assigned to residential mortgage exposures in the New Accord. The assessment team supports this approach.

71. In general, the U.S. standardized approach proposal is more conservative than the Accord in the treatment of national discretion items related to retail exposures and commercial real estate lending. For retail exposures other than residential mortgages, a 75 percent risk weight would be assigned only where such exposures do not exceed US\$1.0 million and where the exposure is part of a well-diversified portfolio. In the proposal, the FBAs sought public comment on appropriate measures of concentration for regulatory retail portfolios. Commercial real estate exposures would not be eligible for a 50 percent risk weight. 
72. The U.S. continuous supervision approach already allows considerable verification of capital position of banks. It should be relatively easy to adapt this to the implementation of the standardized approach, should it be decided to proceed. Certain adjustments in supervisory approach/reporting/off-site analysis will be needed to verify, on a periodic basis, the appropriateness of institutions' use of various credit risk mitigation techniques not currently permitted under risk-based capital rules.

73. If the authorities proceed with the standardized approach on an optional basis, they should give careful consideration to the inherent cherry-picking opportunities in this policy. In particular, banks with mortgage exposures could decide whether or not to adopt the new rule based on its treatment of these assets compared to the current risk-based capital rule.

\section{F. Internal RATings BASEd APPROACH to CREDIt Risk}

74. Criteria: Supervisors should have an effective process in place for determining that banks are meeting the requirements for calculating capital for credit risk using the internal ratings-based (IRB) Approach, including the mechanics of the IRB Approach; rules for corporate, sovereign, bank, retail, and equity exposures; rules for purchased receivables and treatment of expected losses; and recognition of provisions, consistent with the Basel II framework. To meet the criteria, there are three requirements: (i) the country's rules must not deviate materially from the framework; (ii) the country must have an effective approach

for verifying bank compliance with the rules; and (iii) the country must have an approach for verifying the accuracy of bank calculations.

75. The advanced approaches rule does not deviate materially from the Basel II framework. National discretion choices are few and generally result in more conservative capital treatment.

76. The approval requirements to exit parallel run or to move between floors in the qualification period afford ample opportunity for FBAs to assess how the IRB is working in practice. The FBAs have developed an ongoing process to verify bank compliance with the AIRB requirements established by the advanced approaches rule. The goal of the process in each FBA is to ensure that, at each stage of the implementation process, and on an ongoing basis, the bank has met the requirements of the advanced approaches rule, has systems that are working as intended, and is fully prepared before moving to the next phase of qualification. The review process appears robust and includes reports by validation groups and internal audits within the bank, the annual assessment of the controls around Basel II that is presented to the institution's board of directors, and supervisory verification in the form of both Basel II-specific and non-Basel II-specific reviews that evaluate whether the bank continues to satisfy the rule requirements. As only one bank is now in parallel run, it was not possible for assessors to view this process in practice. 
77. At the largest banking organizations, the Basel II process is led by the on-site supervisory team and supported by FRB and OCC qualification teams (QTs), as well as agency policy and quantification resources. These teams were developed by the FRB and OCC to ensure consistency of approach across the largest core banks, where a higher degree of coordination is considered essential to the overall program. The teams comprise staff from multiple areas of and cover the wholesale, retail, securitization, trading book/counterparty credit risk, Pillar 2, and operational risk areas and use a standardized supervisory program. The ability to file accurate, complete, and timely regulatory reports on advanced approaches calculations is a critical consideration in assessing a bank's compliance with the qualification requirements. The accuracy of bank calculations is reviewed through on-site examination work, as well as off-site surveillance based on the regulatory reports.

78. Criteria: Assessors should be satisfied that the supervisor has processes in place for ensuring that the banks meet the appropriate IRB requirements at the outset and on an ongoing basis (paragraph 388) ${ }^{4}$, and that the mechanics of computing the IRB numbers meet the specific rules set out in the framework.

79. The processes already described apply to banks on an ongoing basis as well as during the qualification and parallel run period. Experience in other countries suggests that it is difficult to maintain the degree of focus on Basel II processes that is used in the qualification period to reasonably ensure ongoing compliance. Indeed, that level of ongoing focus may not be necessary. However, when the United States has more banks in the qualification period, it should develop and communicate a more formal expectation for supervisory teams about the extent and nature of high-level and in-depth reviews that are expected and on what cycle, to remain comfortable about the quality of implementation.

80. Criteria: Assessors should seek evidence from supervisors of a robust system to validate the models and outputs of rating systems at the approval stage and when models are modified.

81. Validation is the responsibility of the banking organizations. The FBAs have a robust system for reviewing the results of the validation activities of each bank and providing comments when validation efforts are inadequate. The advanced approaches rule requires a banking organization to conduct ongoing validation of its advanced systems - supervisory review of the validation function is conducted prior to parallel run (if available), during parallel run, and post-parallel run when the institution has qualified. Review of validation documentation and output is a long-standing component of supervisory activities in the United States. Validation process reviews by FBAs are extensive. In addition to process reviews, there are material drill-down reviews on a selection of models chosen for their importance. FBAs also review the validation function when there are significant changes to the models. As is required by Section 23 of the advanced approaches rule, institutions must

\footnotetext{
${ }^{4}$ Basel II: International Convergence of Capital Measurement and Capital Standards: A Revised Framework Comprehensive Version (June 2006) http://www.bis.org/publ/bcbs128.pdf
} 
notify the FBAs when changes are made to the advanced systems that would result in a material change in the bank's risk-weighted asset amount for an exposure type, or when the bank makes any significant change to its modeling assumptions. As in other jurisdictions, FBAs and banks report that achieving the robust high-quality validation is a challenge, but assessors saw evidence of the seriousness with which this is being taken, and the excellent understanding of validation issues. FBAs should ensure that there is consistency in expectations among them going forward.

82. Criteria: Supervisors should verify that the IRB (and AMA) models are actually used by the banks in the context of their capital planning and risk management, and are not primarily a compliance exercise. Internal ratings and loss estimates of IRB banks must be seen to play an essential role in the banks' internal processes and banks must have a credible track record in the use of internal ratings information.

83. The advanced approaches rule requires that the systems and processes used by a bank for risk-based capital purposes be consistent with the bank's internal risk management processes and management information reporting systems. Examiners are expected to identify any differences between AIRB systems and other internal risk management systems and to understand the materiality of these differences. Supervisors expect use of AIRB and AMA systems to identify, monitor, measure, and control risk at the bank.

84. Criteria: Supervisors should have in place a methodology for satisfying themselves that IRB banks' own validation processes are robust. There should, therefore, be evidence of effective challenge functions exercised by banks internally (e.g., by the risk management and/or internal audit functions) as well as by supervisory authorities. Supervisors should be able to articulate their strategy for testing rating systems for reasonableness and show how this strategy operates in practice.

85. The advanced approaches rule places significant emphasis on the need for robust validation processes. The banks' validation process must be independent of the advanced systems' development, implementation, and operation-or the validation process must be subjected to an independent review. In the rule, validation includes an evaluation of conceptual soundness, an ongoing monitoring process, and an outcomes analysis process that includes back-testing. To ensure that banks have robust validation processes, supervisors examine banks' ongoing validation of the AIRB framework, including the risk rating process and parameter estimation. Examiners are expected to determine if the wholesale/retail framework is functioning as intended and if the bank incorporates the findings of validation, audit, and other independent review into their process. Evaluation of the conceptual soundness includes examination of the developmental evidence, model assumptions, and specifications. In practice, the reasonability of risk rating and/or segmentation systems is confirmed through examination of credit risk management and rating processes and transaction testing. This includes appropriate drill-down activities such as replication testing of ratings and examination of override experience. 
86. Criteria: Supervisors should be satisfied that AIRB banks have a methodology for the treatment of downturn conditions that is reasonable and prudentially sound, and produces acceptable results in terms of capital held by banks (see paragraph $468^{52}$ and Basel Committee documents on downturn conditions). This methodology should be in line with good industry practice and reflect the conditions in the country.

87. The FBAs have processes in place to verify that the methodologies with respect to downturn conditions used at each institution are reasonable. Generally, bank methodologies for the treatment of downturn conditions include statistical tests to identify downturn periods, significant segmentation of portfolios to which downturn conditions adjustments apply, use of internal and external data relevant to identifying appropriate downturn adjustments and back-testing, and validation which is subject to review by the FBAs. Assessors encourage the FBAs to make sure that, in addition to this methodology, there is adequate room for judgment to be applied by FBAs in identifying major portfolios subject to market conditions necessitating downturn adjustments.

\section{G. Advanced Measurement ApProach (AMA) FOR Operational Risk}

88. Criteria: A bank must be required to meet an extensive and stringent set of quantitative and qualitative standards to be permitted to use the AMA, and must have monitored the performance of its internal operational risk management for a sufficient period of time before applying the AMA to its operations. Supervisors should be able to demonstrate an effective process for satisfying themselves that banks are meeting the requirements and that results are a reasonable reflection of risks assumed. In particular, banks' data on operational risk experience need to be robust and of sufficient duration and granularity.

89. As with the AIRB, a banking organization must satisfy the extensive AMA requirements in the advanced approaches rule before qualifying to use the advanced approaches to calculate its risk-based capital requirements. Assessors discussed the state of industry preparedness with FBAs. A bank must meet the AMA requirements during the four (or more) quarters that make up its parallel run period. In addition, as a condition of exiting parallel run, the bank must demonstrate that it can meet the criteria on an ongoing basis. To the extent that there are issues, supervisors highlight the concerns to the bank and expect the bank to remediate them within a clearly defined time horizon. U.S. supervisors have been systematically monitoring banks' progress on AMA since 2004, when the first AMA benchmarking exercise took place. The FBAs also conducted/participated in several operational risk LDCEs, the most recent of which took place in 2008. The 2008 LDCE collected detailed information on internal operational loss event data, scenario data, exposure estimates, and range of practice information.

\footnotetext{
${ }^{5}$ Basel II: International Convergence of Capital Measurement and Capital Standards: A Revised Framework Comprehensive Version (June 2006) http://www.bis.org/publ/bcbs128.pdf
} 
90. Criteria: A bank's AMA should be subject to a period of initial monitoring by its supervisors before it can be used for regulatory purposes. Supervisors should be satisfied that a bank's internal system is estimating unexpected operational losses with reasonable accuracy based on internal and external data, scenario analysis, and bank specific inputs. The system must also be capable of supporting an allocation of economic capital for operational risk across business lines and ultimately of improving operational risk management.

91. Banks are subject to initial and ongoing monitoring of their AMA frameworks to ensure that the requirements of the advanced approaches rule are met. This extended monitoring allows supervisors to ensure that a bank's internal system is estimating unexpected operational losses with reasonable accuracy, based on a solid foundation of internal and external loss event data, scenario analysis, and a clear understanding of the business environment across the enterprise. This must be demonstrated during and after parallel run.

92. Criteria: Depending on the operational risk variants used by banks in their jurisdiction, supervisors must have a sufficient number of staff adequately trained in operational risk approaches and must also have a process that allows them to assess on an ongoing basis whether banks continue to meet the quantitative and qualitative standards for application of the AMA.

93. Those in the FBAs with responsibility for work on Basel II implementation have an appropriate understanding of the requirements and what must be in place to qualify a bank using the AMA. All of the FBAs have staff directly responsible for AMA. In each of the core banks, there are individuals on the relationship teams that have specific responsibility for ongoing supervision of the AMA framework. In addition, supporting the relationship teams are AMA quantification experts who provide on- and off-site assistance, and policy experts that assist in examination work and also provide input on interpretative matters.

94. There is an extensive process supporting the ongoing assessment of whether banks continue to meet the quantitative and qualitative requirements for the AMA. In particular, the AMA benchmarking process will continue after the implementation phase of Basel II and be used to guide examiners in ongoing reviews.

\section{H. Pillar 2: Supervisory Review Process}

95. Criteria: Supervisors should have appropriate processes, evidenced by plans and actions, for review of bank processes to assess capital adequacy, risk positions, and quality of capital held. These reviews should cover the four elements referred to in this Principle (adequacy of risk assessment, assessment of capital adequacy, assessment of control environment, compliance with minimum standards). As supervisors will normally adopt a process that is, in part, risk-based and reliance-based and is integrated into their supervisory 
system, supervisors should be able to explain to assessors how these processes meet the Pillar 2 requirements.

96. The FBAs' supervisory program for Pillar $\mathbf{2}$ is a continuation of their longstanding emphasis on the need for institutions to conduct an internal assessment of capital adequacy — beyond minimum regulatory measures—capturing their full risk profile. Consistent with the New Accord, the advanced approaches rule requires that banking organizations subject to the rule have an ICAAP. In July 2008, the FBAs issued final supervisory guidance for Pillar 2, providing institutions with a description of a satisfactory ICAAP. The guidance covers the four elements of Pillar 2 laid out in the Basel II framework. The guidance places particular emphasis on the need for a sound underlying risk management foundation in the ICAAP. It outlines issues that banking organizations should consider when estimating capital needs during times of stress, and notes that banks should be aware that certain capital instruments do not have the same capacity to absorb losses in times of stress as common equity. The guidance also notes the importance of strong corporate governance, including validation and internal audit, as well as the need to hold capital buffers above minimum regulatory capital requirements due to the inherent uncertainty in assessing overall needs.

97. Assessors reviewed this guidance which is comprehensive. As detailed formalized Pillar 2 assessments were not available at the time of assessment, assessors were not able to judge whether the necessary supervisory processes (including appropriate judgment by banks and supervisors) were in place to adequately assess the actual capital levels held by banks. Assessors recommend that FBAs use the Pillar 2 assessment process, and the discussion it leads to with banks, as a tool to assist in ensuring that major banks are holding adequate capital so that Pillar 2 does not become merely a compliance exercise. Considering Pillar 2 approaches by banks in a cross-system, cross-agency process on a regular basis (including at a senior level in FBAs) is desirable. FBAs should conduct such a cross-agency, cross-system review as soon as a sufficient number of Pillar 2 approaches by banks are available, and at regular intervals (at least annually) thereafter.

98. FBAs report that they expect banks to have a fully-functioning Pillar 2 process in place before entering parallel run. The ongoing capital planning and analysis work within financial institutions and recent SCAP exercise has assisted in Pillar 2 development, though the $\mathrm{BCP}$ review more generally suggested that stress testing by banks, which is a core Pillar 2 requirement, needs further development. Pillar 2 requires considerable judgment by banks and supervisors. Experience elsewhere suggests that inculcating Pillar 2 into bank capital planning, risk assessment, and strategy requires a period of adjustment to be effective. Accordingly, assessors believe that the FBAs' approach may encourage a more complianceoriented approach to Pillar 2 by banking organizations than is desired. FBAs should take stock of Pillar 2 implementation with these factors in mind in the near future to ensure that the benefits of an effective Pillar 2 are being realized. This should be one of the matters considered in the cross-system review of Pillar 2 implementation suggested above. 
99. The standardized approach proposed rule does not contain a well-elaborated Pillar 2 requirement. The existing, generally-worded supervisory expectations are that banks will assess their capital in relation to their risks. As noted in the BCP assessment, the current prompt corrective action provisions of U.S. regulations, and supervisory expectation, mean that all banks are effectively expected to have capital above the minimum ratios. In addition, there are clear abilities for authorities to take action related to capital deficiencies. Currently, capital is assessed in the supervisory process.

100. If the standardized approach proceeds, further Pillar 2 guidance would be required to meet the spirit of Principles 1 and 2 of Pillar 2 for small and medium-size banks. Assessors discussed with FBAs their approach to Pillar 2, if the standardized approach was to be adopted. FBAs indicated supervisory expectations would have to be developed based in part on the Pillar 2 guidance now in place for larger banks. Authorities should not underestimate the challenge in developing and implementing an ICAAP-like process for smaller and mid-size banks that is effective in encouraging banks that are outliers to allocate appropriate capital. Nor should they underestimate the adjustments in their own monitoring, analysis, and supervisory tools to consider Pillar 2 issues for those banks.

101. Criteria: Supervisors should be able to demonstrate how banks are required to manage important risks not directly addressed in Pillar 1. This includes interest rate risk in the banking book, credit concentration risk, counterparty credit risk, and other aspects such as stress testing noted in Pillar 2. Supervisors should demonstrate a sound knowledge of these areas in their banks, and of appropriate practices.

102. Pillar 2 guidance includes risks not addressed in Pillar 1. The FBAs place particular emphasis on risk concentrations, both intra-risk and cross-risk. With respect to credit risk, banks must include both single-name as well as sectoral/geographic concentrations in their estimates of overall capital needs relating to credit risk-especially during times of stress. Banks must also be able to understand the potential for cross-risk concentrations (often latent during benign periods) to affect overall capital needs during stressful periods. These issues are highlighted clearly in the U.S. Pillar 2 supervisory guidance and are among the issues given greatest attention by the FBAs in their Pillar 2 evaluations. Banks should be able to assess the potential for all risk types to affect capital adequacy. Even though capital may not be an effective mitigant for all types of risk, all risks may have the potential to affect capital adequacy. Liquidity, reputational, and strategic risks may be among those risks difficult to quantify in terms of specific capital attributions, however their impact on overall capital adequacy can still be substantial.

\section{The FBAs emphasize that stress testing is an integral part of assessing overall} capital adequacy. Even the best quantitative modeling has limitations and shortcomings that need to be supplemented by additional risk measures such as stress tests. Importantly, the FBAs expect banking organizations to hold capital buffers above estimated capital needseven if quantitative models are robust and have been fully validated-because of the inherent uncertainty in assessing overall capital adequacy. 
104. For some of these risks, core banks are using economic capital methodologies to estimate their impact on capital.

105. In a number of these areas, as in other jurisdictions, further advancements need to be made in relating capital to risk. However, assessors are of the view that banks and supervisors are fully capable of making that progress. FBAs should conduct targeted regular cross-system focused reviews in these areas going forward to assess banks against best practice and supervisory expectations. The results of these reviews should be considered by senior FBA staff in their assessment of system-wide performance, and as an input into the possible need for further guidance.

\section{Pillar 3: Disclosure ANd Market Discipline}

106. Criteria: Supervisors should be able to demonstrate to assessors that rules have been put in place, not necessarily by the regulator, to require banks to make qualitative and quantitative Pillar 3 disclosures with at least the minimum frequency, as a result of some combination of: accounting principles, regulatory requirements, formal supervisory requirements, condition of qualifying for a particular Basel II approach, publication of parts of supervisory reports, supervisory guidance, or moral suasion. In particular, supervisors should be satisfied that banks are meeting IRB disclosure requirements. Any gaps should be sufficiently immaterial so as not to undercut the effectiveness of Pillar 3.

107. Pillar 3 has been fully incorporated into the advanced approaches rule. The disclosures included in the rule are consistent with the Pillar 3 requirements of the Basel II Accord.

108. Each consolidated banking organization (except if they are a subsidiary of a non-U.S. banking organization subject to comparable disclosure requirements in its home country) is subject to the disclosure requirements once they have qualified to use the advanced approaches rule for regulatory capital purposes. Disclosures are quarterly, with qualitative disclosures that typically do not change each quarter disclosed annually (provided any significant changes to these are disclosed in the interim). FBAs have not dictated the specific location or medium where the disclosures must be provided.

109. The Pillar 3 disclosure requirements for the proposed standardized approach are generally consistent with the Basel II Accord.

110. Criteria: Supervisors should have a periodic process in place to satisfy themselves that they, or qualified third parties, validate the comprehensiveness and accuracy of bank disclosures relative to Pillar 3 standards, and that banks are provided with any appropriate feedback.

111. The primary FBA will determine if a bank is meeting the Pillar 3 disclosure requirements through its ongoing supervision process. In addition, institutions are required to have a formal disclosure policy approved by the board of directors that addresses its approach to determining the disclosures they make. The policy must address the 
associated internal controls, disclosure controls, and procedures. The board and senior management are responsible for establishing and maintaining an effective internal control structure over the disclosures required. One or more members of the senior management team must also attest that the disclosures made by the institution meet the requirements of the advanced approaches rule.

\section{It is too early for assessors to see this process in action at banks or by}

supervisors. However, given the way the U.S. continuous supervision process operates, as reviewed during the FSAP, assessors believe this plan for Pillar 3 implementation is appropriate. Once a significant number of mandatory banks are making Pillar 3 disclosures, FBAs should conduct a cross-system, cross-agency review of these and satisfy themselves as to their appropriateness. This would accord the needed priority and forge consistency in supervisory consideration, and such reviews of disclosures should be repeated from time to time. 